\title{
Numerical Study of the Effect of a Power Plant Cooling Water Discharge in the Montevideo Bay
}

\author{
Mónica Fossati, Pablo Santoro, Santiago Urrestarazu, \\ and Ismael Piedra-Cueva
}

Institute of Fluid Mechanics and Environmental Engineering, School of Engineering, Universidad de la Republica, J. Herrera y Reissig 565, Montevideo, Uruguay

Correspondence should be addressed to Mónica Fossati, mfossati@fing.edu.uy

Received 30 December 2010; Accepted 21 February 2011

Academic Editor: Jürgen Geiser

Copyright (C) 2011 Mónica Fossati et al. This is an open access article distributed under the Creative Commons Attribution License, which permits unrestricted use, distribution, and reproduction in any medium, provided the original work is properly cited.

The numerical simulation of the water temperature in the Río de la Plata River and Montevideo's Bay was done using the numerical model of finite elements RMA-10 in its 2D vertical integrated mode. Parameters involved in the formulations of thermal exchange with the atmosphere were adjusted using measurements of water temperature in several locations of the water body. After calibrating the model, it was used to represent the operation of a power plant located in Montevideo's Bay. This central takes water from the bay in order to cool its generators and also discharges high-temperature water into the bay. The correct representation of temperatures at the water intake and discharge of the plant reflects that the model is able to represent the operation of the central. Several analysis were made to study the thermal plume, the effects of the water discharge on the water intake of the power plant, and the effect on environmental variables of the study area like currents.

\section{Introduction}

The National Electric Power Company (UTE) has a thermal power plant in the city of Montevideo, located on the Montevideo Bay (Figure 1), called Central Batlle. This power plant takes water from the Montevideo Bay and discharges into the bay again after using it to cool the condensers of the plant. More precisely, the discharge point is located inside the Montevideo Port.

Currents in the Montevideo Bay are primarily induced by winds of various speeds and directions, which are highly variable in time, by tides, and, to a lesser degree, by the salinity wedge in the navigation channel.

The far-field water temperature is primarily affected by air temperature and solar radiation. Winds affect also its spatial variation. In the near-field, the thermal plume at the channel outlet is affected primarily by the exit water temperature and flow rate. The outlet 


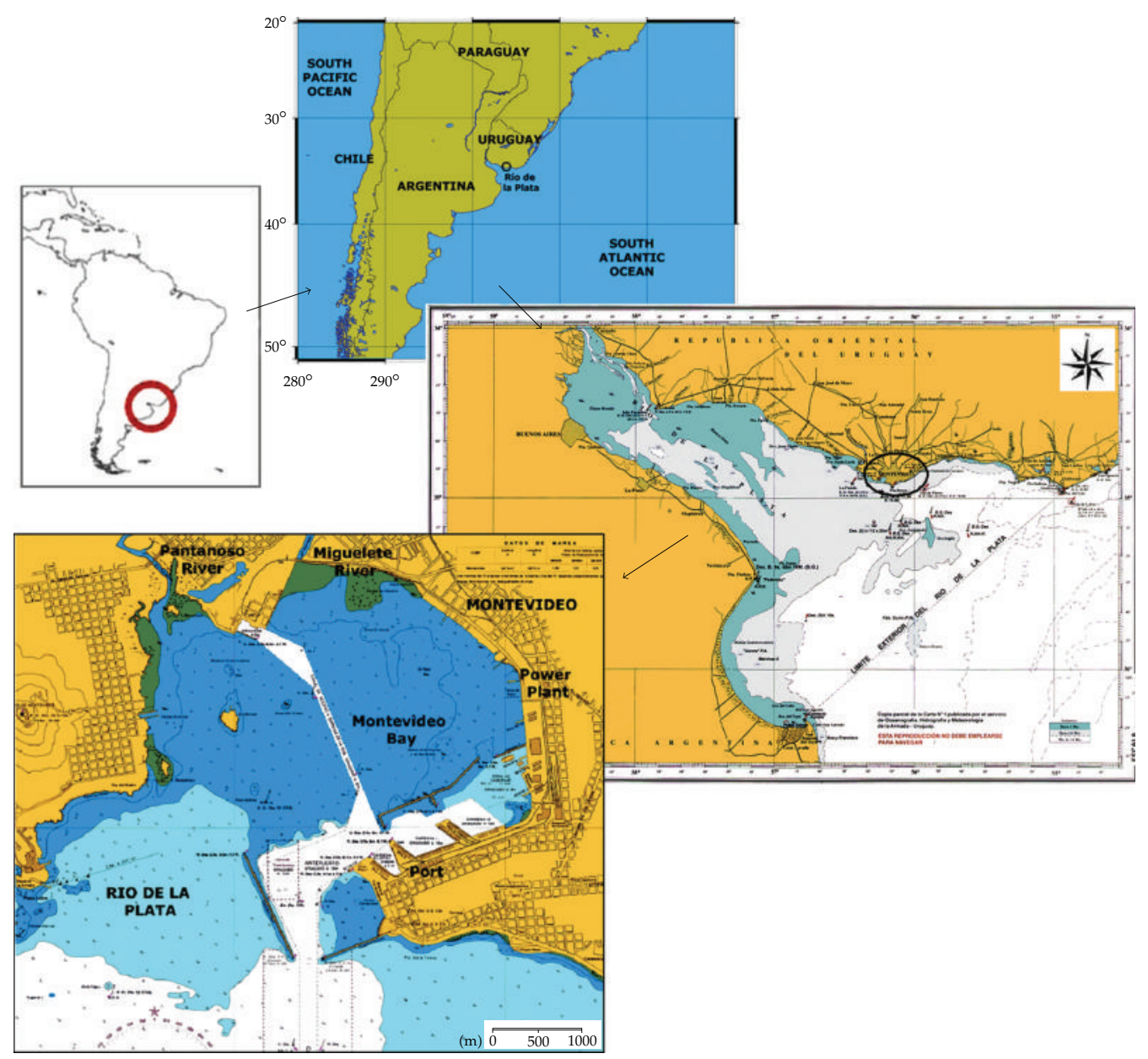

Figure 1: Study area location.

water has a temperature of $11^{\circ} \mathrm{C}-14^{\circ} \mathrm{C}$ above the far-field water temperature, depending on the season. Both the flow and temperature difference between the water intake and discharge of the power plant modify the flow pattern in both areas and, therefore, affect the currents and temperature fields.

Numerical models are simplified mathematical representations of physical systems and processes. A numerical model can be constructed as a one-, two-, or three-dimensional model in accordance with the dominant spatial directions of the physical processes [1-3]. In this study, a three-dimensional model for the entire water body would be computationally challenging. It was found that a two-dimensional model for the entire water body would resolve properly the horizontal variation of water temperature in the near and far field area.

A dynamic model is used to take into account antecedent conditions for currents and temperature. Both of these parameters are affected by long-term physical processes such as wind speed, direction, and heat input. The main mechanism for the formation of the temperature field around the heated effluents is its mixing with the ambient water or, in other words, dilution. 
The research on discharge of cooling water from power plants into water bodies has been of interest for many years [4-7]. It is not only of great theoretical importance to the study of the transfer and movement of thermal discharge water, but also of great economic value. Without proper management methods, the thermal wastes would probably do great harm to the ecological health of the surrounding water regions.

Therefore, a numerical model has been developed for the Montevideo Bay to study the changes in the currents and temperature field due to the intake and discharge of cooling water and to identify if the temperature of the water intake is to some extend affected by the discharge of heated water in the harbor.

\section{Study Area}

Uruguay is located in the east coast of South America between Argentina and Brazil. It has an area of $176,215 \mathrm{~km}^{2}$ and 3.46 million inhabitants. Most of its political limits are water bodies including rivers, estuaries, lakes, and the Atlantic Ocean. To the southwest, in the limit with Argentina, lies the Río de la Plata. This water body is located between $34^{\circ} 00^{\prime}-36^{\circ} 10^{\prime}$ South latitude and $55^{\circ} 00^{\prime}-58^{\circ} 10^{\prime}$ West longitude and has the second largest basin of South America $\left(3.170 .000 \mathrm{~km}^{2}\right)$ after the Amazonic one (Figure 1). The Paraná and Uruguay rivers provide more than $97 \%$ of the continental water inlet with an annual mean flow of $22.000 \mathrm{~m}^{3} / \mathrm{s}$. Other minor rivers and streams discharge along both coastal shores of the Rio de la Plata. The fresh water mixes with the oceanic water creating a zone of brackish waters in the Rio de la Plata that behaves as a microtidal estuary. The flow dynamic in the Rio de la Plata and the Maritime Front is very complex due to the topographic variation of the river and the influence of continental flows, astronomical and meteorological tides coming from the ocean, and the local winds. River level variations produced by astronomical tides are lower than those generated by the wind and oceanic waves.

Montevideo is located on the central zone of the Rio de la Plata, where the salinity shows significant fluctuations as a function of the seasons, fresh water flow, and tides. The coastal zone of Montevideo includes several beaches, hard points, a big bay (Montevideo's Bay), and navigation channels. Montevideo Bay is a big enclosed water body and covers an area of around $12 \mathrm{~km}^{2}$. Water depth reaches $5 \mathrm{~m}$ in the outer part of the bay, but the average depth is between $1 \mathrm{~m}$ to $1.5 \mathrm{~m}$ in the inner part. Navigation channels are around $11 \mathrm{~m}$ deep. The bay receives municipal effluents and two polluted streams, Pantanoso and Miguelete, where multiple industries discharge. Moreover, a large thermoelectric power station and the major petroleum refinery are located next to the bay.

\section{Existing Power Plant and Operation}

Built in 1930, the power station consists of different units that are run according to energy demand. The first unit to go into operation is called sixth unit and can generate a maximum power of $125 \mathrm{MW}$. When this unit is not sufficient to meet the demand, the fifth unit, whose generating capacity reaches $80 \mathrm{MW}$, is turned on. Sometimes this sequence of operation is reversed; the 5th is dispatched first and then the 6th if necessary. Units 5 and 6 have been operational since 1970 and 1976, respectively.

A continuous flow of cooling fresh water is required to absorb heat from the steam turbine condenser. The flow intake and discharge of the power plant depends on the operating schedule, that is, units that are running. The 5th unit requires a cooling flow of $3.9 \mathrm{~m}^{3} / \mathrm{s}$, 


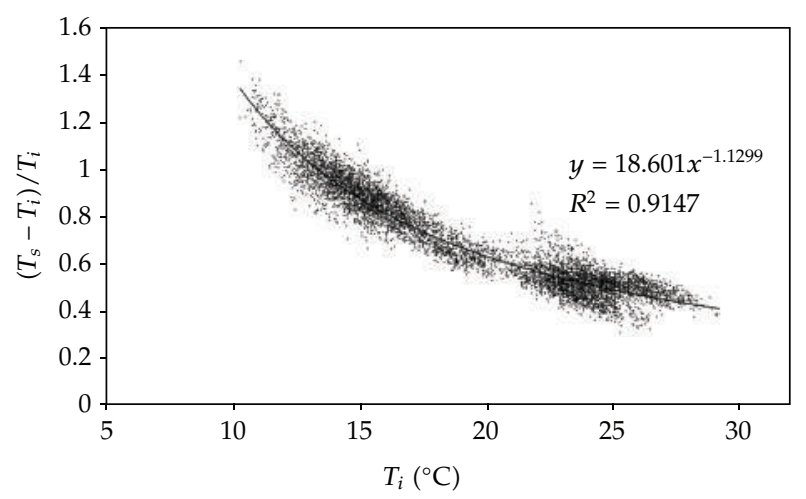

Figure 2: Input and output temperature fit equation for the units 5 and 6 working together from data between September 2003 and March 2007.

while the 6th unit has a higher flow rate, equal to $4.4 \mathrm{~m}^{3} / \mathrm{s}$. The discharge point is located about $600 \mathrm{~m}$ south from the water intake inside the dock of Montevideo Port.

Submerged multiport diffusers are generally thought to be the most effective means for handling the rapid initial dilution of thermal discharges, since heated water is discharged from many spaced ports at high velocity, forming a turbulent jet into the receiving water body (see, e.g., [4]). However, Central Batlle power station discharges in the Montevideo Port through a single open channel with low initial mixing. The water depth at the discharge point is about $6 \mathrm{~m}$.

The power plant administration has been automatically monitoring the temperature of water in the intake and discharge zone continuously since 2003 with a time frequency of 30 minutes, including periods when the plant is turned off. The analysis of temperature data recorded at the intake and discharge of the power plant shows a behavior captured by (3.1). The higher the temperature of the cooling water, the greater the thermal output to the bay for a given flow rate. The rated thermal loading of the condenser unit represents the average heat output of the condenser unit

$$
T_{o}-T_{i}=A \times T_{i}^{B},
$$

where $T_{o}=$ output temperature of power plant, $T_{i}=$ input temperature of power plant, and $\mathrm{A}$ and $\mathrm{B}$ are parameters.

Data from the period September 2003 to March 2007 were selected to adjust the tuning parameters of (3.1) for the different operation schemes of the plant.

For the case where the two units (5th and 6th) are dispatched together, (3.1) was adjusted considering as inlet and outlet temperature the average of each unit input and outlet temperature, respectively.

The result is a set of parameters A and B as a function of the diagram of operation of the plant, the 5th unit operating alone, the 6th unit operating alone, and both units working together, which are presented in Table 1 together with the $R^{2}$ parameter. Figure 2 shows an example of the adjustment of the temperature data for the diagram of operation of both units. Note the good quality of the fit obtained in all cases. 
Table 1: Coefficients A and B for the inlet and outlet temperature power plan formulation for the three operating schemes.

\begin{tabular}{lccc}
\hline Operating scheme & Coefficient A & Coefficient B & Fit $\left(R^{2}\right)$ \\
\hline 5th Unit & 14,9630 & $-0,0540$ & 0,7223 \\
6th Unit & 6,5187 & 0,2171 & 0,7479 \\
5th and 6th Unit & 18,6010 & $-0,1299$ & 0,9147 \\
\hline
\end{tabular}

\section{Materials and Methods}

A good description of topographic variations and coastline is needed to simulate the hydrodynamic details of the Montevideo Bay. Moreover, due to the complex flow distribution along the bay mouth, the simulation of the flow around the Río de la Plata and Maritime front is also required to properly represent the hydrodynamic in the bay. Therefore, the domain of calculation covers from the mouths of major tributaries, the Paraná and Uruguay rivers in its western border, to the continental shelf in the Atlantic Ocean.

The finite element model RMA-10 [8], which was designed to analyze systems using the 3D shallow water equations, is applied. The model is capable of couple the spatial density variations induced by salinity and temperature gradients to the hydrodynamic calculations. This enables the model to simulate phenomena such as saline wedges and thermal plumes. RMA-10 has been previously applied to this kind of studies; see, for instance, Golder Associates, 2001 [9].

Because of the very shallow depth of the bay, no stratification can develop, and the system can be regarded as well mixed. RMA-10 was used in a vertical averaged mode but keeping the coupling between salinity and temperature gradients to the velocities in order to model the velocity and temperature fields. Considering the limitations implied by the depth averaging in the deeper part of the outer region of the Rio de la Plata, the results in that area must be analyzed carefully.

\subsection{Model Description}

The model resolves the set of equations derived from a combination of Reynolds form of the Navier-Stokes equations, the volume continuity equation, the advection diffusion equation for salinity or temperature transport, and an equation of state relating water density to salinity or temperature. In Cartesian coordinates, the governing equations are the following:

The momentum equations

$$
\begin{aligned}
& \rho \cdot\left(\frac{\partial u}{\partial t}+u \frac{\partial u}{\partial x}+v \frac{\partial u}{\partial y}+w \frac{\partial u}{\partial z}\right)-\frac{\partial}{\partial x}\left(\varepsilon_{x x} \frac{\partial u}{\partial x}\right)-\frac{\partial}{\partial y}\left(\varepsilon_{x y} \frac{\partial u}{\partial y}\right)-\frac{\partial}{\partial z}\left(\varepsilon_{x z} \frac{\partial u}{\partial z}\right)+\frac{\partial p}{\partial x}-\Gamma_{x}=0 \\
& \rho \cdot\left(\frac{\partial v}{\partial t}+u \frac{\partial v}{\partial x}+v \frac{\partial v}{\partial y}+w \frac{\partial v}{\partial z}\right)-\frac{\partial}{\partial x}\left(\varepsilon_{y x} \frac{\partial v}{\partial x}\right)-\frac{\partial}{\partial y}\left(\varepsilon_{y y} \frac{\partial v}{\partial y}\right)-\frac{\partial}{\partial z}\left(\varepsilon_{y z} \frac{\partial v}{\partial z}\right)+\frac{\partial p}{\partial y}-\Gamma_{y}=0 \\
& \rho \cdot\left(\frac{\partial w}{\partial t}+u \frac{\partial w}{\partial x}+v \frac{\partial w}{\partial y}+w \frac{\partial w}{\partial z}\right)-\frac{\partial}{\partial x}\left(\varepsilon_{z x} \frac{\partial w}{\partial x}\right)-\frac{\partial}{\partial y}\left(\varepsilon_{z y} \frac{\partial w}{\partial y}\right) \\
& -\frac{\partial}{\partial z}\left(\varepsilon_{z z} \frac{\partial w}{\partial z}\right)+\frac{\partial p}{\partial z}+\rho \cdot g-\Gamma_{z}=0
\end{aligned}
$$


the continuity equation

$$
\frac{\partial u}{\partial x}+\frac{\partial v}{\partial y}+\frac{\partial w}{\partial z}=0
$$

the advection diffusion equation

$$
\begin{aligned}
& \frac{\partial s}{\partial t}+u \frac{\partial s}{\partial x}+v \frac{\partial s}{\partial y}+w \frac{\partial s}{\partial z}-\frac{\partial}{\partial x}\left(D_{x} \frac{\partial s}{\partial x}\right)-\frac{\partial}{\partial y}\left(D_{y} \frac{\partial s}{\partial y}\right)-\frac{\partial}{\partial z}\left(D_{z} \frac{\partial s}{\partial z}\right)-\theta_{s}=0 \\
& \frac{\partial T}{\partial t}+u \frac{\partial T}{\partial x}+v \frac{\partial T}{\partial y}+w \frac{\partial T}{\partial z}-\frac{\partial}{\partial x}\left(D_{x} \frac{\partial T}{\partial x}\right)-\frac{\partial}{\partial y}\left(D_{y} \frac{\partial T}{\partial y}\right)-\frac{\partial}{\partial z}\left(D_{z} \frac{\partial T}{\partial z}\right)-\theta_{T}=0
\end{aligned}
$$

and the equation of state

$$
\rho=F(s, T)
$$

where $x, y, z=$ the Cartesian coordinate system, $u, v, w=$ velocities in the Cartesian directions, $t=$ time, $p=$ water pressure, $D_{x}, D_{y}, D_{z}=$ the eddy diffusion coefficients, $\varepsilon_{x x}, \varepsilon_{x y}, \varepsilon_{x z}, \varepsilon_{y x}, \varepsilon_{y y}, \varepsilon_{y z}, \varepsilon_{z x}, \varepsilon_{z y}, \varepsilon_{z z}=$ the turbulent eddy coefficients, $g=$ the acceleration due to gravity, $\rho=$ water density, $\Gamma_{x}, \Gamma_{y}, \Gamma_{z}=$ the external forces components, $s=$ salinity, $T=$ temperature, and $\theta_{s}, \theta_{T}=$ the source/sink for salinity/temperature.

The basic equations, with appropriate boundary and initial conditions, are integrated numerically using the finite elements method. The vertical component of the momentum equation is simplified following the hydrostatic approximation, and thus its vertical integration determines the pressure field, and, in turn, the horizontal pressure gradients which are substituted in the horizontal components of the momentum equation. A horizontal turbulence-closure scheme is used to dynamically set eddy viscosity terms in the momentum equations and horizontal diffusion coefficients in the transport equations. The Smagorinsky method of describing horizontal eddy-viscosity and diffusivity coefficients uses meshelement velocity gradients and areas in a generalization of a mixing-length representation for these terms. The model also maintains a heat budget for every element, which accounts for heat inputs and losses. This heat budget incorporates net short-wave input, long-wave radiation, long-wave back radiation, evaporation, and conduction with the atmosphere. A more detailed model description can be found in [10,11].

To simulate the temperature distribution, it is necessary to consider heat exchange through the water surface. This exchange includes both radiation transfer and diffusive processes. The upper surface boundary condition is formulated in relation to the heat flux through it. RMA-10 states this condition according to the following formulation:

$$
Q=K\left(T_{s}-T_{\mathrm{eq}}\right),
$$

where $Q=$ heat flux $\left(\mathrm{KJ} / \mathrm{m}^{2} \mathrm{hr}\right), K=$ coefficient of heat transfer $\left(\mathrm{KJ} / \mathrm{m}^{2} \mathrm{hr}{ }^{\circ} \mathrm{C}\right), T_{S}=$ water surface temperature $\left({ }^{\circ} \mathrm{C}\right)$, and $T_{\mathrm{eq}}=$ equilibrium temperature $\left({ }^{\circ} \mathrm{C}\right)$. The equilibrium 
temperature and the coefficient of heat transfer $\left(\mathrm{BTU} / \mathrm{ft}^{2} \mathrm{dí}{ }^{\circ} \mathrm{F}\right)$ are given by the following expressions:

$$
\begin{gathered}
T_{\text {eqf }}=\frac{Q_{\text {sn }}}{23+f(W) \times(\beta+0.255)}+T_{d}, \\
K=23+\left(\beta_{W}+0.255\right) \times 17 \times W_{2},
\end{gathered}
$$

where $T_{\text {eqf }}=$ equilibrium temperature $\left({ }^{\circ} \mathrm{F}\right), Q_{s n}=$ short wave net solar radiation $\left(\mathrm{BTU} / \mathrm{ft}^{2} \mathrm{día}\right)$, $T_{d}=$ dew point temperature $\left({ }^{\circ} \mathrm{F}\right), f(W)=$ empirical function of wind velocity (BTU/ $\mathrm{ft}^{2}$ day $\left.\mathrm{mmHg}\right)\left(f(W)=17 \cdot W^{2}\right), W_{2}=2$ meter wind velocity, and $\beta=$ function of temperature $\left(\mathrm{mmHg} /{ }^{\circ} \mathrm{F}\right)$

$$
\begin{gathered}
\beta=0.255-0.0085 T_{m}+0.000204 T_{m}^{2} \\
T_{m}=0.5 \times\left(T_{s}+T_{d}\right), \\
\beta_{W}=0.255-0.0085 T_{s}+0.000204 T_{s}^{2} .
\end{gathered}
$$

\subsection{Implementation of the Model}

Figure 3(up-left) shows the horizontal configuration of the finite element mesh used, and Figure 3(up-right) shows a mesh detail in Montevideo Bay. It was structured on the basis of an east-west and north-south coordinate system. The figure shows the triangular finite elements mesh. Mesh size depends on the accuracy required in the different parts of the domain. In total, there are 7,462 elements and 15,526 nodes, with element side sizes ranging from $10 \mathrm{~km}$ in the ocean boundary up to $50 \mathrm{~m}$ within the bay.

The bathymetry of the domain was constructed from mapping information from nautical charts of the Rio de la Plata and the continental shelf. Figure 3(down) shows the detail of the bathymetry of the Montevideo Bay. It clearly shows the deepest parts corresponding to the Port, the La Teja channel, and the breakwaters.

Simulations were made considering the temporal variability of the river discharge, tides, and winds. Water surface elevation is prescribed at the open boundary condition. The input flow is separated in two sections, one for the discharge of both Uruguay and Paraná Guazú rivers and the second one for the discharge of Paraná-Las Palmas river. Daily data from the Argentine Water Institute (INA) was used as well as wind speed and wind direction recorded at Punta Brava station. A constant value of $35 \mathrm{ppt}$ is specified for salinity at the ocean boundary, and a constant water temperature of $20^{\circ} \mathrm{C}$ was applied in both water boundaries, river and ocean. Flow contribution from the Miguelete and Pantanoso streams were also considered through the specification of the mean averaged values, $0.54 \mathrm{~m}^{3} / \mathrm{s}$ for Pantanoso and $1.593 \mathrm{~m}^{3} / \mathrm{s}$ for Miguelete.

In addition, the thermal modulus requires information on cooling water inlet and outlet canal flow rates which affect near-field flow circulation conditions: power plant cooling water temperatures in the outlet channel which, in conjunction with the flow rates, determines the amount of discharged heat and near field thermal dispersion, evaporation coefficients ( $\mathrm{A}$ and $\mathrm{B}$ ) for the entire water surface area to determine heat loss to the atmosphere, altitude of the cooling water body and cloud cover to compute solar heat input, and dry and wet bulb air temperatures for calculating the heat exchange between 
the water surface and the atmosphere. Meteorological time series were obtained from the meteorological station of Punta Brava, operated by the oceanographic, hydrographic, and meteorological service of army (SOHMA).

\subsection{Model Calibration}

The approach used in this study to calibrate the RMA10 model was to match the simulated results and field measurements as closely as possible to observations by adjusting the parameters requiring calibration within acceptable ranges.

The model calibration procedure is summarized below.

(i) The first step was to adjust the Manning's $n$ values to calibrate the hydrodynamic model together with dispersion coefficient (eddy viscosity) to calibrate the salinity transport.

(ii) The second step was to adjust some constants to calibrate the thermal module for water temperatures in the far field.

(iii) The third step was to calibrate the model of the power plant intake and discharge.

\subsubsection{Hydrodynamic Calibration}

Simulations were performed to determine water surface elevation, currents, and the salinity field resulting from the interaction of continental river discharge with the tide entering from the ocean, winds, and salinity gradients. The heat exchange with the atmosphere and the thermal field induced by the operation of the power plant were not included at this stage.

Salinity spin-up simulation was conducted from August 2003 to January 2004. The calibration period was February and March 2004, and the validation was done for April 2004. The hydrodynamic calibration was performed comparing model result with hydrodynamic data. For comparison of water surface elevation, hourly records of water surface level at stations of La Paloma, Montevideo, Colonia, and Buenos Aires were used. Comparison of currents was based on measurements of velocity performed at two points off the coast of Montevideo. They were obtained using acoustic current profiler (ADCP). There is no available salinity data during the simulation time. However, salinity was calibrated in former studies [11]. The location of the measuring stations is presented in Figure 4.

\subsubsection{Thermal Calibration}

The variability of water temperature in the domain was modeled including the interchange with the atmosphere. The following information is required at this step: evaporation coefficients (A and B) to determine heat loss to the atmosphere, cloud cover for calculating solar heat input to the bay, and dry and wet bulb air temperatures to compute the heat exchange with the atmosphere.

Thermal model calibration was performed by adjusting two parameters. One is an atmospheric attenuation factor that represents the atmosphere's capacity to intercept some of the solar radiation that passes through it, and the second parameter is a solar extinction coefficient representing the rate of decrease of the radiation absorbed by the water with increasing depth. These parameters were determined from the comparison of temperature 


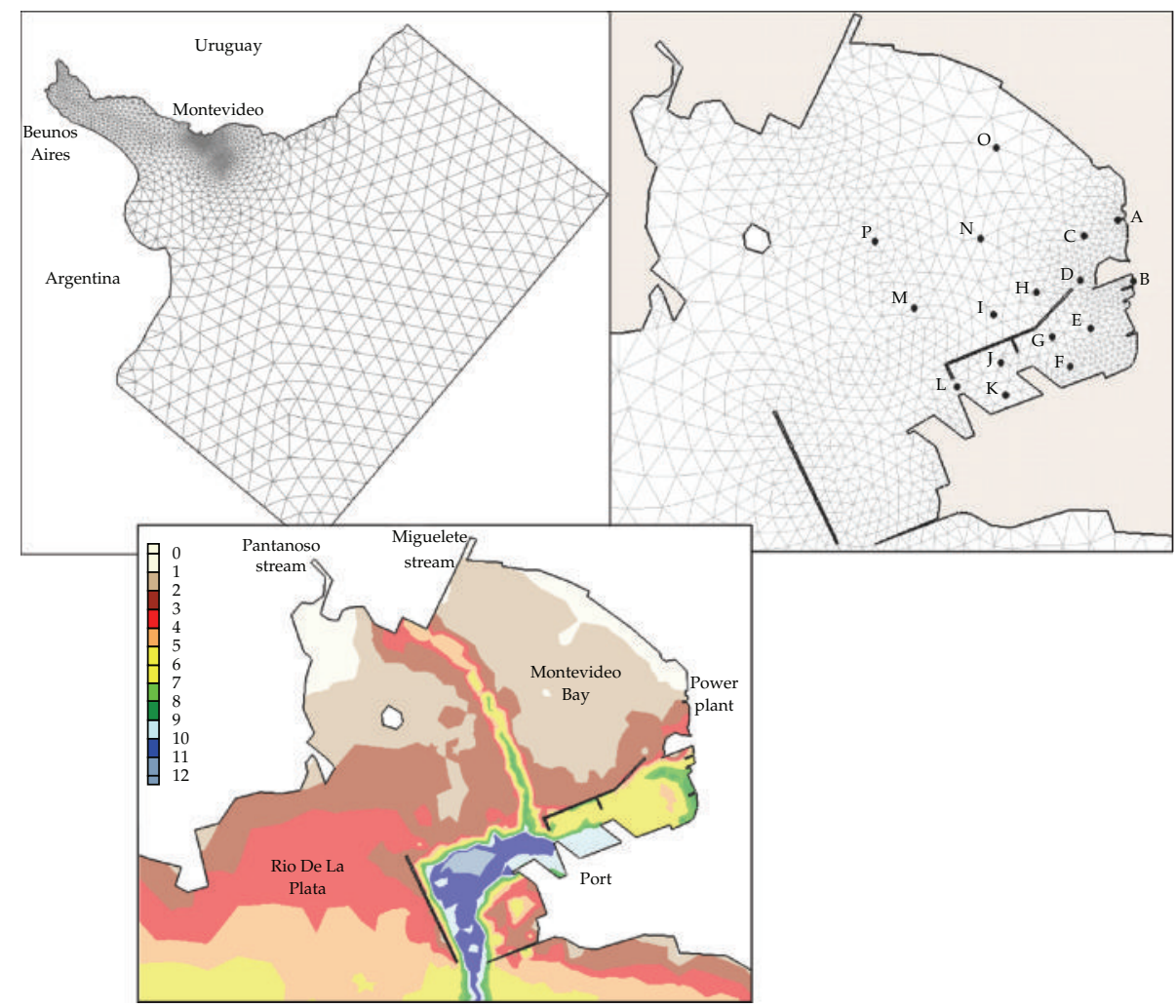

Figure 3: General and detail in Montevideo Bay of the finite element model grid and bathymetry detail in Montevideo Bay.

registered and calculated by the model in two control points, where measurements were available during the simulated period. One set of data corresponds to the data collected twice a day in the meteorological station of Punta Brava, and the second one corresponds to the data collected in the input channel of the power plant in Montevideo Bay. The simulation period, February 1st to March 15th 2004, was purposely selected during a time in which the power plant was not in operation (so that the measured temperature in the bay data is not affected by the power plant). The location of the stations is presented in Figure 4.

After the calibration, a period of 45 days during the winter of 2004 was simulated (July 20th to August 20th, 2004) to assess the ability of the model to represent the temperature field during a period much colder than the one used for calibration. An accurate representation of the observed temperature in the control points during the validation period allowed us to verify the adjustment of the simulated variables.

\subsubsection{Power Plant Calibration}

Finally, the model was calibrated regarding the power plant income and discharge. The existing conditions in the Montevideo Bay were simulated using actual flow data from the power plant. The flow rate depends on the condenser units and pumps in operation. As we mentioned above, the 5 th units requires a flow of $3.9 \mathrm{~m}^{3} / \mathrm{s}$, the 6 th unit $4.4 \mathrm{~m}^{3} / \mathrm{s}$, and both units together a total water flow of $8.3 \mathrm{~m}^{3} / \mathrm{s}$. 


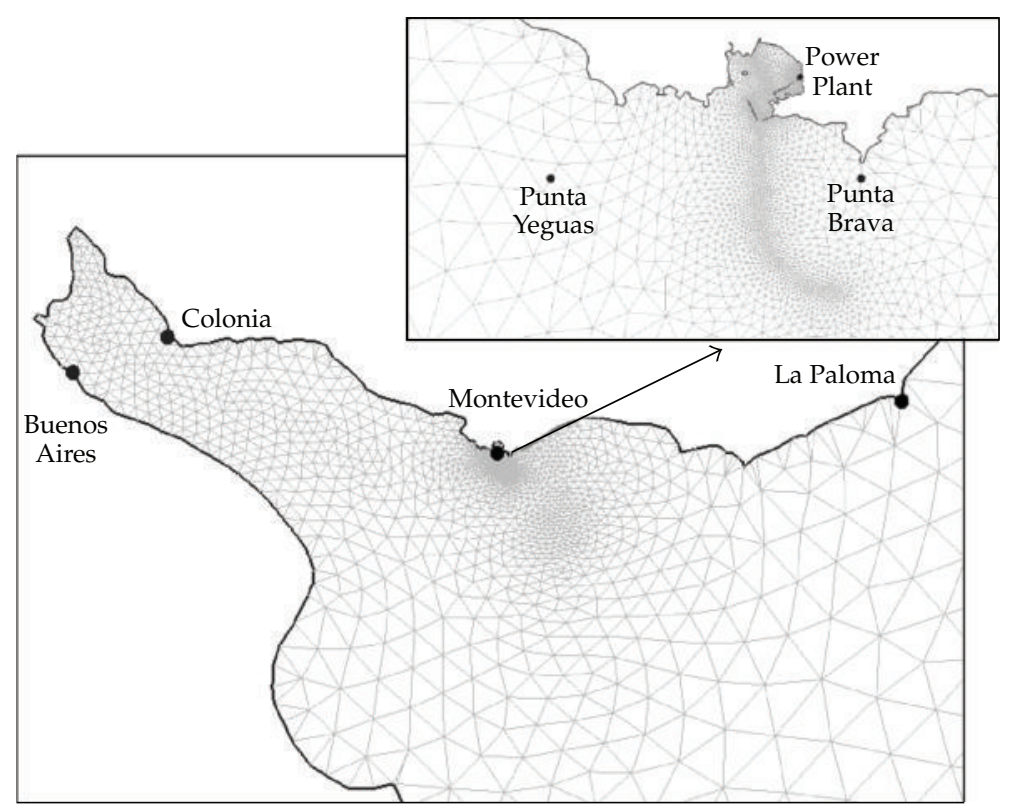

Figure 4: Location of the water surface elevation Rio de la Plata stations (Buenos Aires, Colonia, Montevideo, and La Paloma), ADCP stations (Punta Yeguas and Punta Brava), and temperature stations (Punta Brava and Power Plant).

The RMA-10 model can simulate the cooling water circulation used by a power plant. The model calculates the water temperature of the discharge according to the intake water, the flow, and power of the plant. Nevertheless, as we mentioned above, the data collected in the plant show that the heat exchange in the plant is dependent on the intake water flow and temperature. So, the formulation included in the RMA-10 was substituted by the formulation obtained from the data ((3.1) with parameters presented in Table 1).

The selected calibration period extended from March 19th to July 16th, 2004. During this period, the power plant operated almost continuously although with alternating schemes in terms of units dispatched.

The model was validated with the comparison of the water temperature modeled and measured in the power plant discharge zone. Due to the temperature variation of the bay between warm and cold seasons of the year, time periods representatives of both seasons were simulated.

\subsection{Model Applications}

Once the model was calibrated and validated, several analyses were made to study the thermal plume, the effects of the water discharge on the water intake of the power plant, and the effect on environmental variables of the study area like currents. The period between March 19th and July 16th, 2004, was simulated. During that period, the power plant worked almost without interruption although with different operating schemes.

In order to evaluate the effect of the power plant cooling water discharge on the environment, simulations were done twice: one with the power plant operating and a second one with the power plant off. 
Temperature differences between the simulation with the plant turned on minus the one with the plant turned off $(\Delta T)$ were computed to determine the degree of affectation produced by the plant discharge on the temperature in the bay and at the plant water intake. Thus, the time frequency and spatial distribution of the temperature increase were analyzed.

Several control points were defined in the bay and port, including the intake and discharge of the plant, for further analyses of the results obtained by the model (Figure 3). Point $\mathrm{A}$ is located in the water intake of the plant, and point $\mathrm{B}$ represents the outflow of the power plant. Points E, F, G, K, J, and L are located inside the port area, C and D are located close to the intake of the power plant, $\mathrm{H}$ and I are located close to the port zone, and $\mathrm{M}, \mathrm{N}, \mathrm{O}$ and $\mathrm{P}$ are located far from the outflow of the power plant.

To analyze the effect of the intake and outflow generated by the power plant over the hydrodynamic field, the directional currents frequency distributions were calculated in both simulations, with the plant on and off. The directional analysis was done considering the 8 nautical directions. The mean and maximum velocity values for each simulation in the control points were also calculated.

\section{Results}

\subsection{Model Calibration and Validation}

\subsubsection{Hydrodynamic Calibration}

After the calibration process, it was found that the hydrodynamic model accurately represents the time variability of water level and currents. As an example, Figure 5(a) presents a comparison between measured and modeled surface water levels in four stations of the Río de la Plata. It is shown that the model results reproduce the temporal variation of recorded water surface elevation, especially in the Montevideo area. In addition, a comparison between modeled and observed velocities is presented in Figure 5(b). The results again show a good agreement.

\subsubsection{Thermal Calibration}

The comparison of the measured and modeled temperature for the period February to April 2004 at Punta Brava station is presented in Figure 6. It shows that the model reproduces both the general behavior and the major fluctuations of the observed temperature. For example, during the months of February and March, measurements generally range between $21^{\circ} \mathrm{C}$ and $25^{\circ} \mathrm{C}$, and the model represents temperatures between $22^{\circ} \mathrm{C}$ and $24^{\circ} \mathrm{C}$. It is further noted that during the month of March, temperatures decrease, and the model reproduces the behavior. Figure 7 shows the comparison of the measured and modeled temperature in the point of the power plant water intake. It shows that the model reproduces the temperature during the simulation period, also showing the daily cycle of water temperature. On some days, there are differences between the measured temperatures and that obtained from the model but generally not exceeding $4^{\circ} \mathrm{C}$.

The obtained results during the validation stage of the thermal model (Figure 8) show that without changing model parameters, the quality of the temperature modeling was maintained, reproducing water temperature variations in the Río de la Plata coastal zone and in Montevideo Bay. 

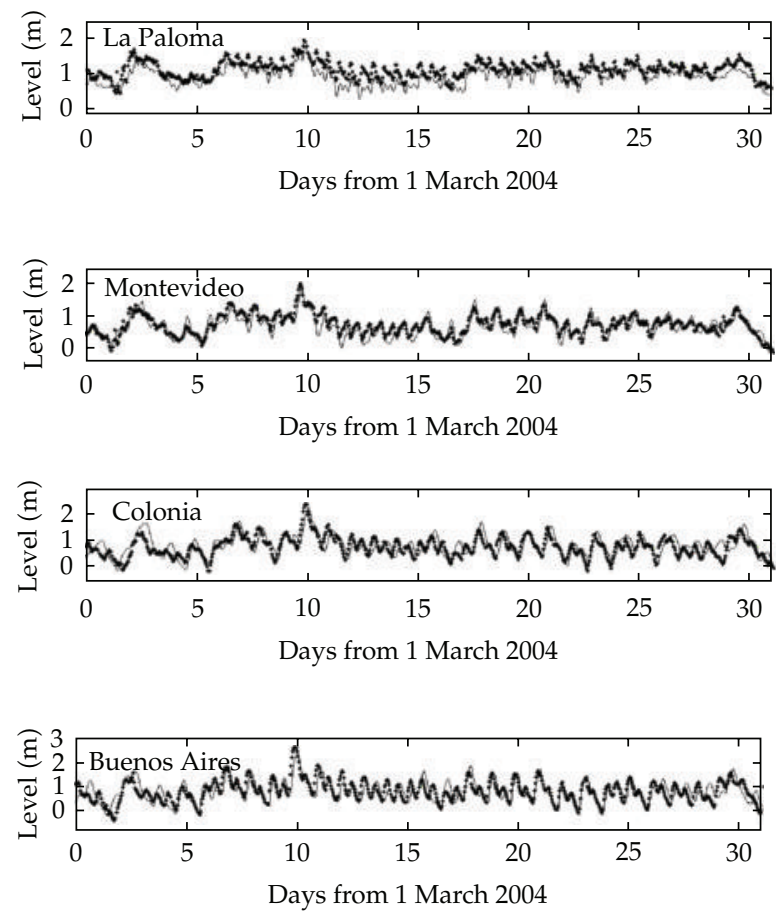

- Model

- Measured

(a)

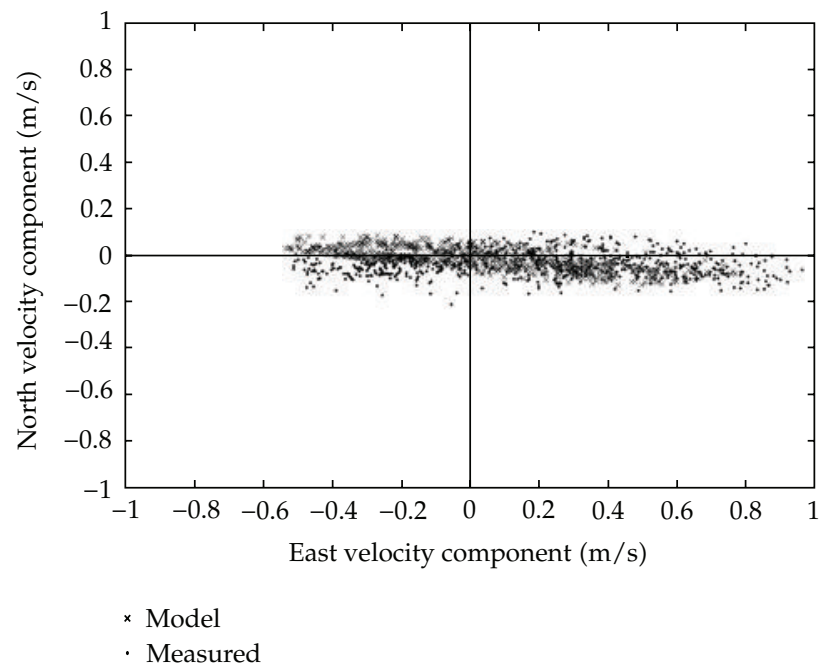

(b)

Figure 5: Temporal water level variation obtained with the model and measured in La Paloma, Montevideo, Colonia, and Buenos Aires during the calibration period March 2004 (a). Comparison of the spatial variation of the modeled and measured currents in Punta Brava during the days between 17 and 29 February 2004 (b). 


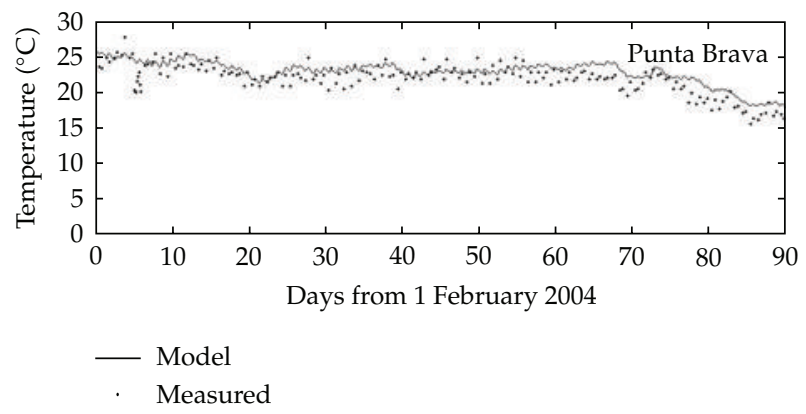

Figure 6: Comparison of the measured and modeled water temperature in Punta Brava station from February, March, and April 2004.

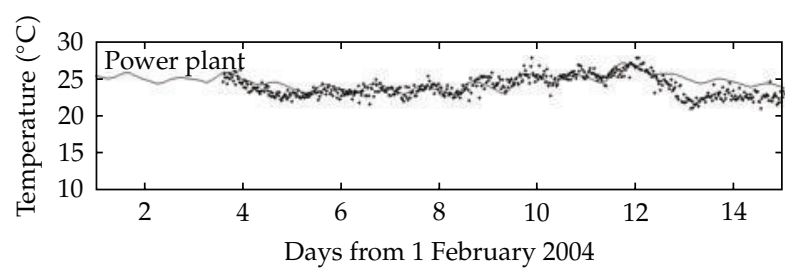

(a)

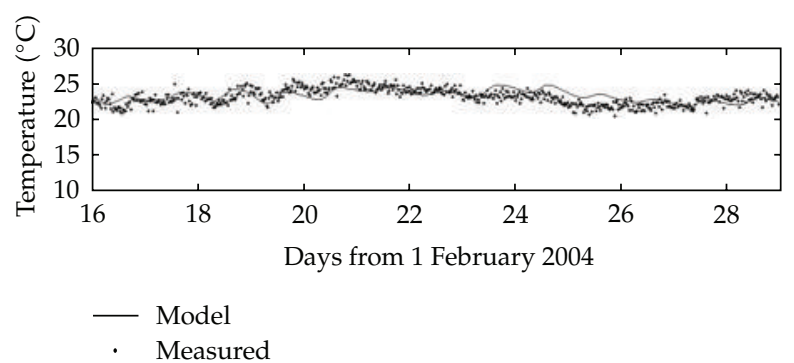

(b)

Figure 7: Comparison of the measured and modeled water temperature in power plant station from February 2004.

\subsubsection{Hydrodynamic Validation}

After the second calibration step, the model dynamically coupled with temperature was verified. The surface water levels and currents calculated with the model were compared with observed values. The results show (Figure 9) that the hydrodynamic model maintains the good agreement between observed and modeled data.

\subsubsection{Power Plant Validation}

Most of the time, the power station works with 5th and 6th units in operation simultaneously. Using the parameters for that operation scheme, a good representation of the power plant effect of temperature on the discharge was obtained with the model. For example, Figures 10 and 11 show the comparison of temperatures measured and modeled in two time periods 


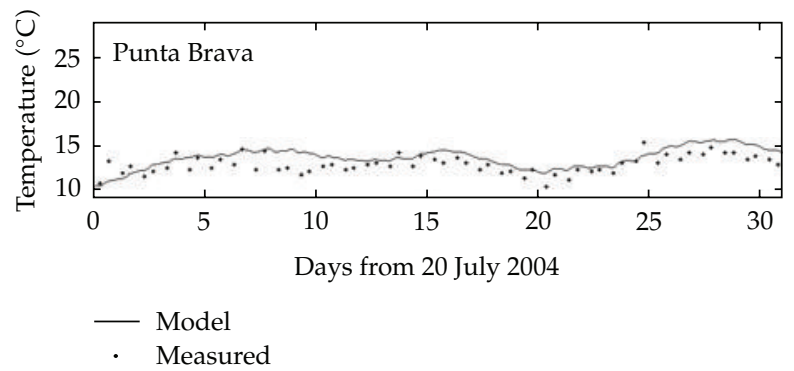

(a)

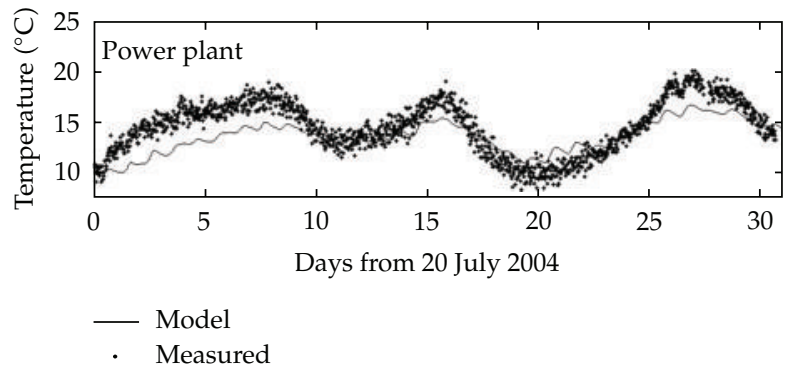

(b)

Figure 8: Comparison of the measured and modeled water temperature in Punta Brava and power plant station in July 2004.

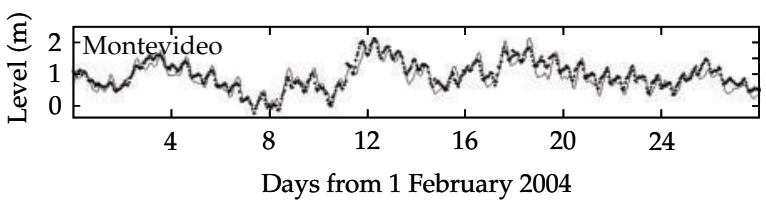

(a)

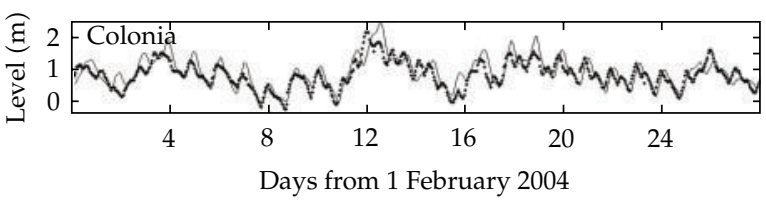

(b)

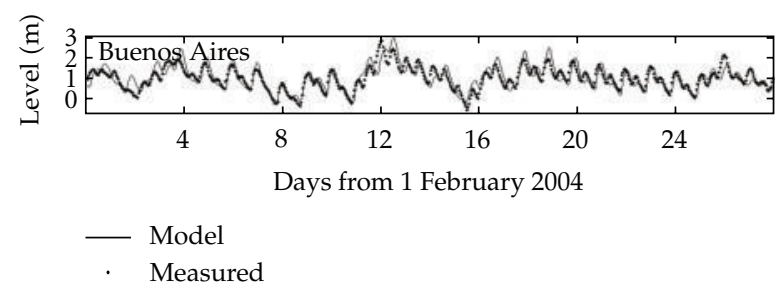

(c)

Figure 9: Comparison of water level measured and obtained with the model in three stations of the Rio de la Plata during February 2004. 


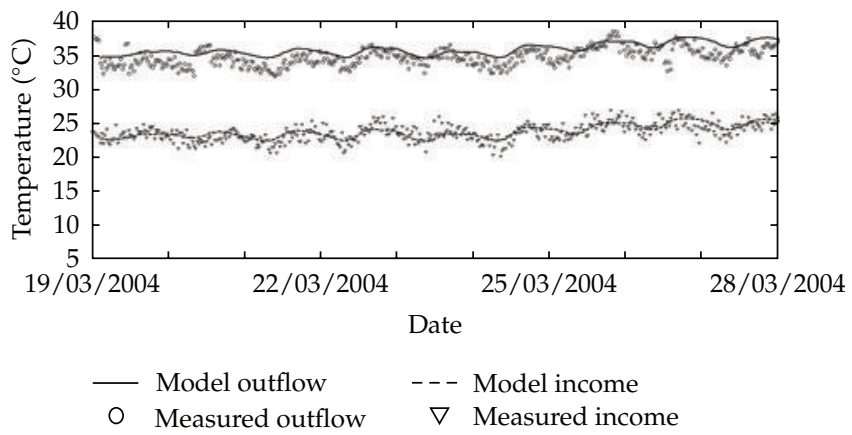

Figure 10: Comparison of the measured and modeled temperatures in the income and outflow of the power plant with the 5th and 6th units in operation for the days between 19 and 28 March 2004.

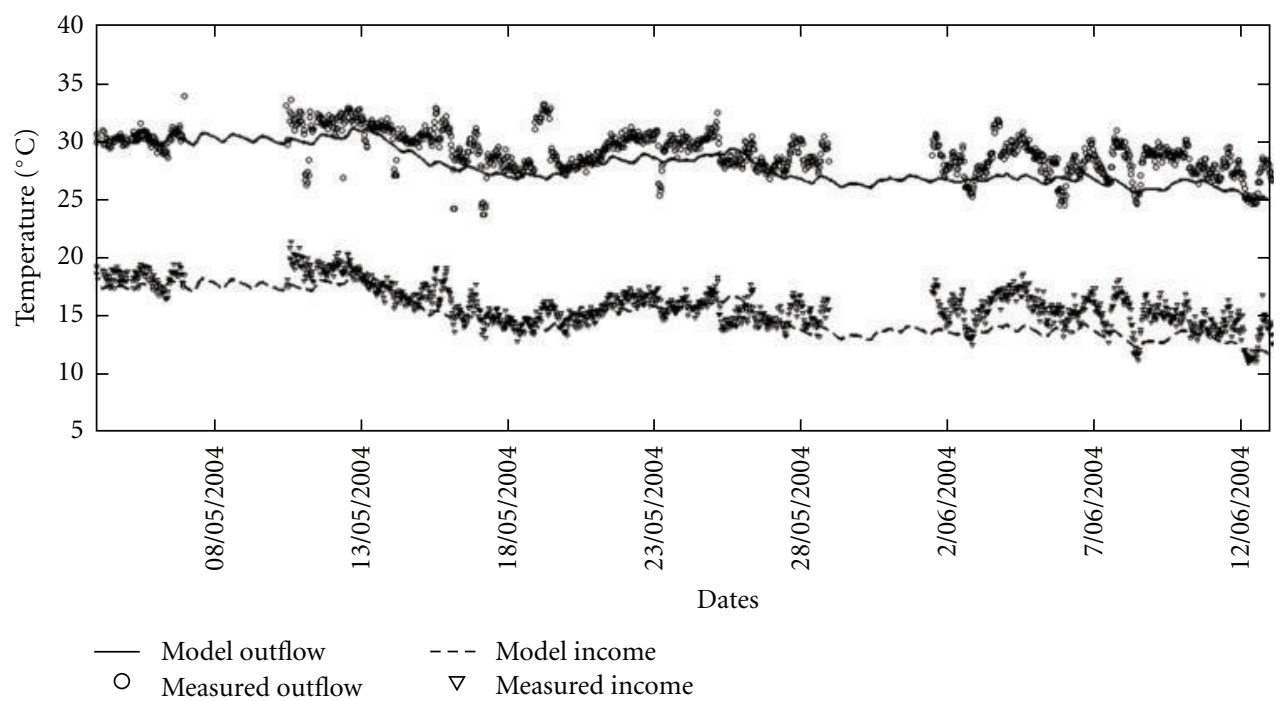

Figure 11: Comparison of the measured and modeled temperatures in the income and outflow of the power plant with the 5th and 6th units in operation for the days between 3 May and 15 June 2004.

in which both units were running. The model correctly reproduces the overall behavior of temperature at the water intake and in the discharge, both in warmer months where temperatures are between $20^{\circ} \mathrm{C}$ and $25^{\circ} \mathrm{C}$, as in the cold months of June and July in which the temperature in the bay has an average value of $15^{\circ} \mathrm{C}$.

Figure 12 shows the comparison between the measured and modeled temperatures in the water intake and outflow of the plant with only the 5th unit in operation, and Figure 13 shows the same comparison but for a case with the 6th unit in operation. Both cases show a good representation by the model of the water temperature in the zone associated with the plant.

The temperature plume nearby the zone of discharge and the currents generated for the intake and outflow of the plant are presented in Figures 14 and 15. These images show different time snaps corresponding to different seasons and power plant operation schemes. They clearly show the area of intake and discharge of water from the plant with higher water 


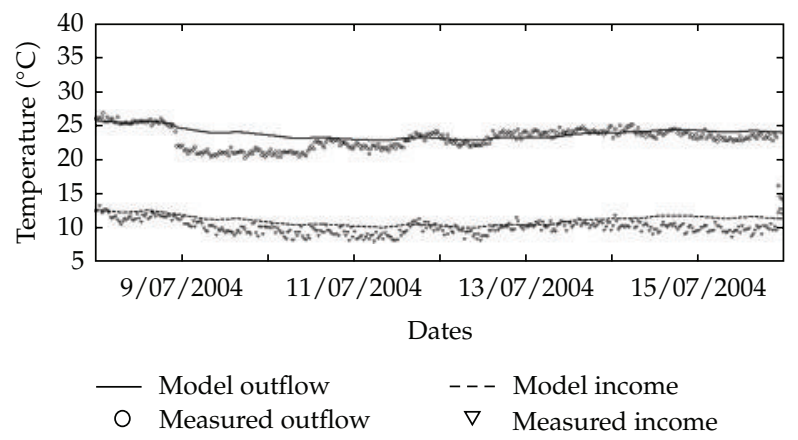

Figure 12: Comparison of the measured and modeled temperatures in the income and outflow of the power plant with the 5th units in operation for the days between 8 and 16 July 2004.

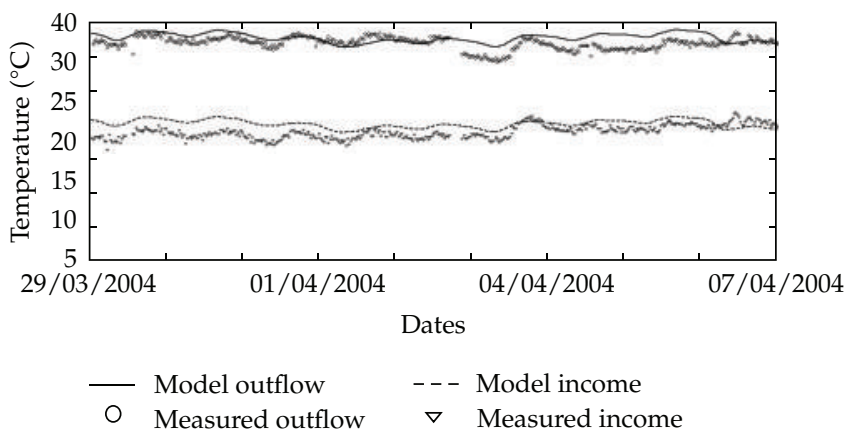

Figure 13: Comparison of the measured and modeled temperatures in the income and outflow of the power plant with the 6th units in operation for the days between 29 March and 7 April 2004.

temperatures and flow intensities in the discharge area and with a current going out of the port which is directed to the plant intake zone.

\subsection{Power Plant Intake and Discharge Effects}

\subsubsection{Influence of the Discharge in the Intake Water Temperature}

Figure 16 shows the temporal variation of water temperature in the intake of the power plant calculated with the plant turned on and turned off. It shows that the calculated values are different in both scenarios, meaning that temperature of water intake is affected by the power plant discharge. The frequency distribution of temperature difference corresponding to the control point located near the water intake shows that $26.5 \%$ of the time, the temperature increment is less than $0.2^{\circ} \mathrm{C}, 53.7 \%$ of time, it is less than $0.6^{\circ} \mathrm{C}$, and $70.7 \%$ of the time, it is less than $1^{\circ} \mathrm{C}$ (only $29.3 \%$ of the time the temperature increment is higher than $1^{\circ} \mathrm{C}$ ). This result is very important, since it could change the working point of the turbine, with the resulting loss of efficiency. The maximum value of temperature increase during the simulation period was $2.3^{\circ} \mathrm{C}$.

The time evolution of water temperature with the power plant turned on and turned off and the histogram of $\Delta T$ in the points $\mathrm{H}$ and $\mathrm{J}$ are presented in Figures 17 and 18, 


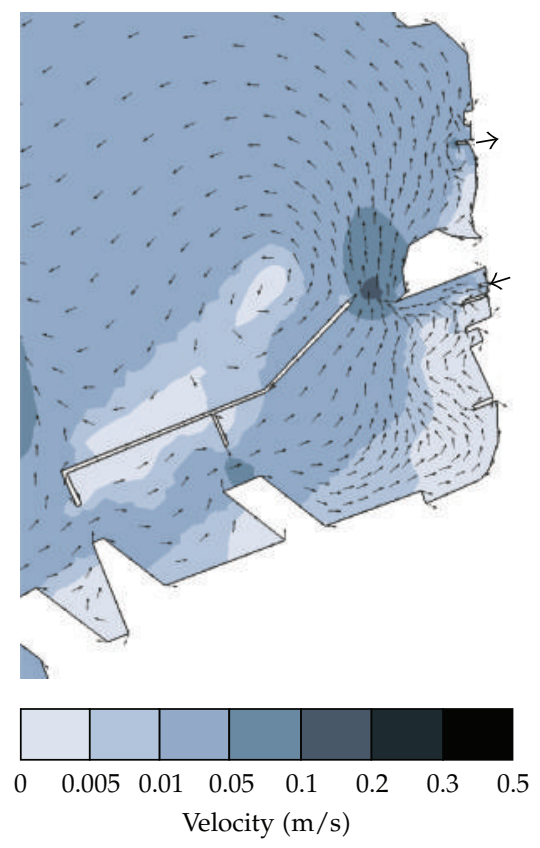

(a)

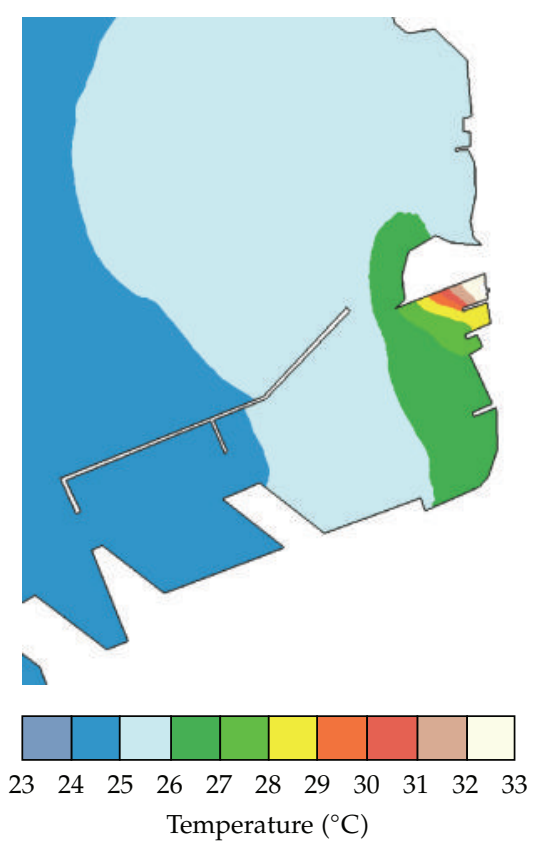

(b)

Figure 14: Velocity field and temperature field obtained with the model for the March 30th 14:00 hours with the 6th unit of the power plan in operation.

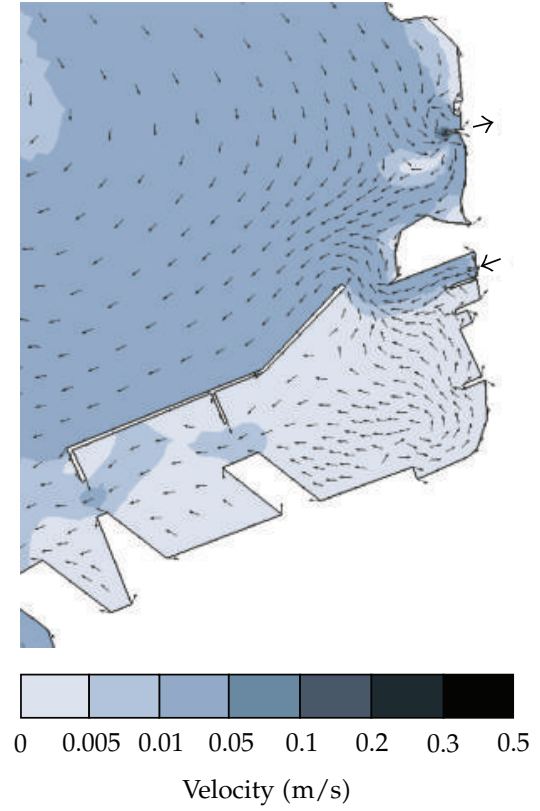

(a)

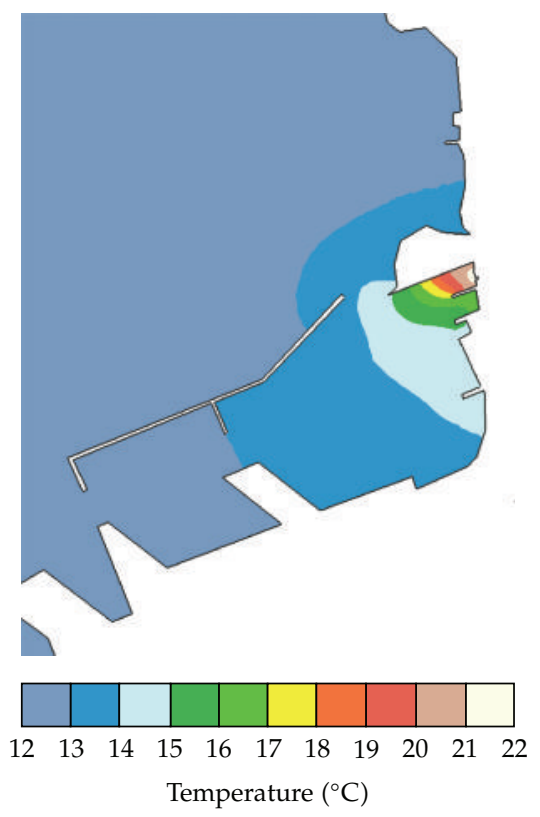

(b)

Figure 15: Velocity field and temperature field obtained with the model for the 17 June 18:30 hours with the 5th and 6th units of the Power Plan in operation. 


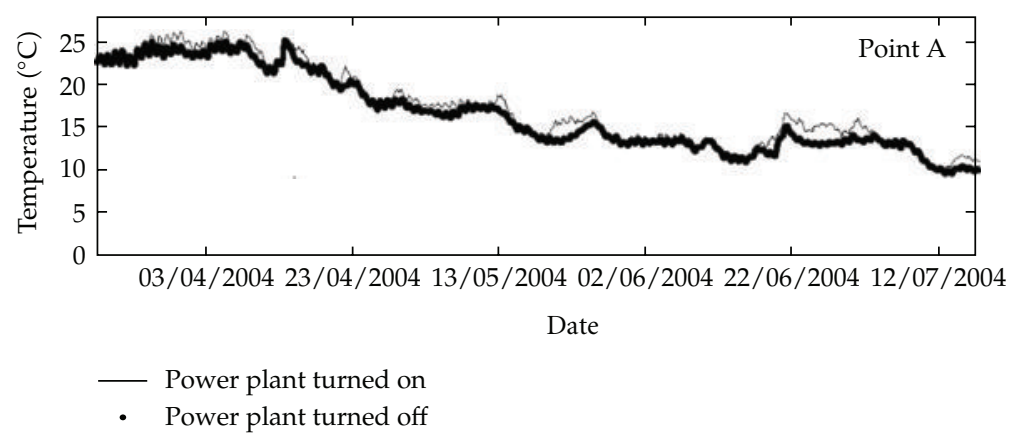

(a)

\begin{tabular}{cc}
\hline$\Delta T$ & Frequency $(\%)$ \\
\hline$<0.2$ & 26.9 \\
$<0.4$ & 42.4 \\
$<0.6$ & 53.7 \\
$<0.8$ & 61.1 \\
$<1$ & 70.7 \\
$<1.2$ & 77.6 \\
$<1.4$ & 84.7 \\
$<1.6$ & 89.9 \\
$<1.8$ & 92.6 \\
$<2$ & 95.3 \\
$<2.2$ & 98 \\
$<2.4$ & 100 \\
\hline
\end{tabular}

(b)

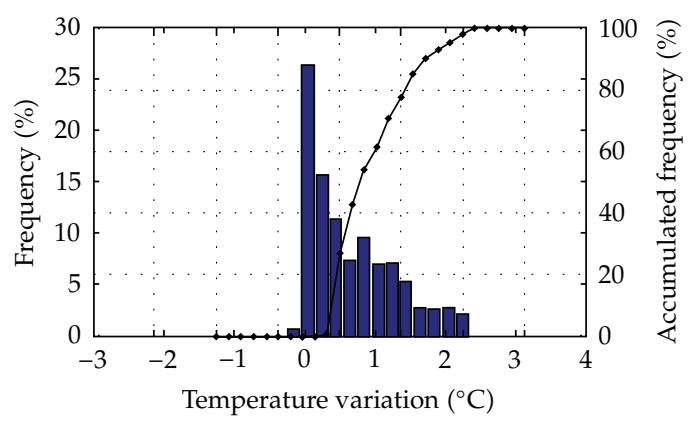

(c)

Figure 16: Time evolution of the water temperature calculated with the model in the income power plant (point A) with the power plant turned on and turned off. Histogram of the $\Delta T$ in point $\mathrm{A}$.

respectively. It is noticeable that there is a greater impact on the water temperature in the port area represented by the point $\mathrm{J}$ than in the outside area represented by the point $\mathrm{H}$.

Figure 19 presents the residual value of the temperature increment. It shows that the mean value of temperature increment near the power plant water intake is about $0.75^{\circ} \mathrm{C}$.

\subsubsection{Influence of the Cooling Flow Intake Outflow in the Bay Circulation}

The influence of the power plant cooling water intake discharge on the circulation pattern can be obtained comparing the directional distribution of currents at the control points for both cases of power plant turned on and turned off. It was found that the power plant has greater effects in points $C$ and $D$ besides the intake and outflow points $A$ and B. Figure 20 shows the results for point $C$ and $D$ with most frequent flow direction towards the south in the case of power plant turned off. But in the case of the power plant turned on, northern velocities increase their frequencies, inverting the direction of the residual flow. Results of residual flow presented in Figure 21 confirm this finding.

Regarding the flow intensity, the results also show an increase of velocity in the area related with points $C$ and $D$. Table 2 presents the mean and maximum flow intensity obtained with the model in both simulations.

Finally, Figure 21 presents the residual flow distribution for both cases (power plant turned on and off). It shows that when the power plant is turned off, the flow directions is from the bay toward the port, but when the power plant is on, the flow direction is inverted, flowing from the port towards the bay. 


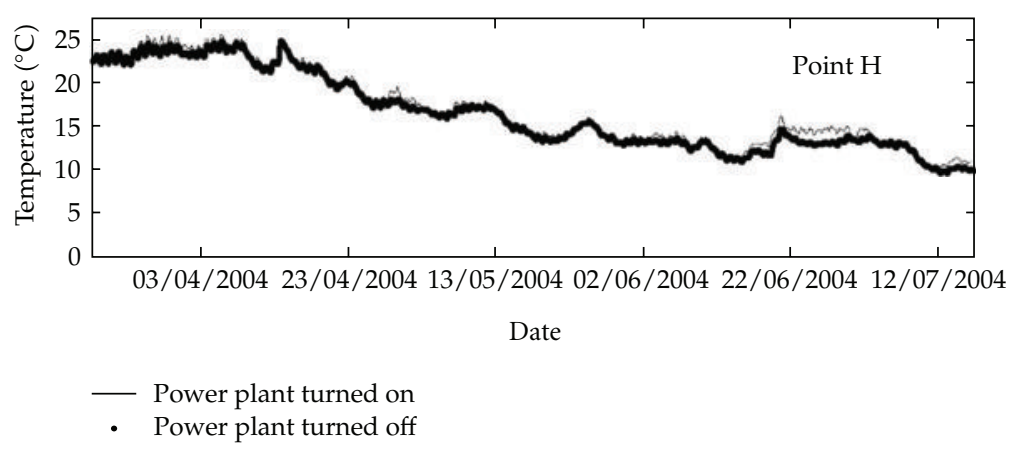

(a)

\begin{tabular}{cc}
\hline$\Delta T$ & Frequency (\%) \\
\hline$<0$ & 0 \\
$<0.2$ & 27.8 \\
$<0.4$ & 52.8 \\
$<0.6$ & 69.6 \\
$<0.8$ & 81 \\
$<1$ & 88.5 \\
$<1.2$ & 93.5 \\
$<1.4$ & 96.9 \\
$<1.6$ & 99.1 \\
$<1.8$ & 100 \\
\hline
\end{tabular}

(b)

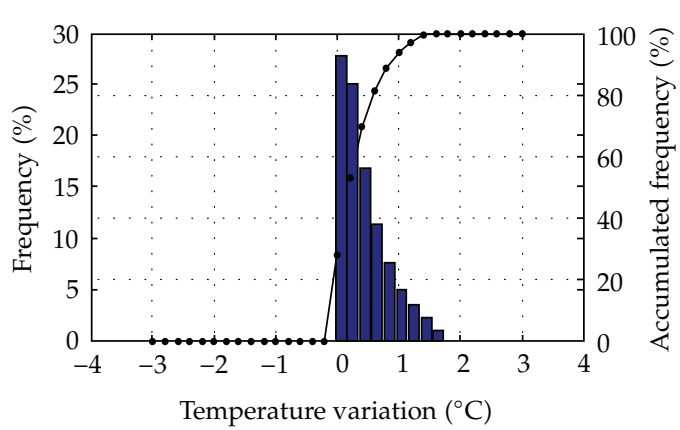

(c)

Figure 17: Time evolution of the water temperature calculated with the model in the zone outside the port (point $\mathrm{H}$ ) with the power plant turned on and turned off. Histogram of the $\Delta T$ in point $H$.

Table 2: Mean and maximum velocity calculated for the model in different locations of the Montevideo Bay considering the power plant turned off and turned on.

\begin{tabular}{|c|c|c|c|c|}
\hline \multirow{2}{*}{ Location } & \multicolumn{2}{|c|}{ Mean velocity $(\mathrm{cm} / \mathrm{s})$} & \multicolumn{2}{|c|}{ Maximum velocity $(\mathrm{cm} / \mathrm{s})$} \\
\hline & $\begin{array}{c}\text { Power plant } \\
\text { turned off }\end{array}$ & $\begin{array}{c}\text { Power plant } \\
\text { turned on }\end{array}$ & $\begin{array}{c}\text { Power plant } \\
\text { turned off }\end{array}$ & $\begin{array}{c}\text { Power plant } \\
\text { turned on }\end{array}$ \\
\hline $\mathrm{A}$ & 0,69 & 19,13 & 4,54 & 34,06 \\
\hline B & 0,00 & 11,32 & 0,00 & 15,56 \\
\hline $\mathrm{C}$ & 3,29 & 3,22 & 16,67 & 17,31 \\
\hline $\mathrm{D}$ & 5,62 & 5,47 & 27,85 & 29,08 \\
\hline E & 0,96 & 1,00 & 6,11 & 6,03 \\
\hline $\mathrm{F}$ & 0,57 & 0,60 & 3,86 & 3,80 \\
\hline G & 1,37 & 1,32 & 6,27 & 6,10 \\
\hline $\mathrm{H}$ & 3,01 & 3,01 & 14,67 & 14,41 \\
\hline I & 3,92 & 3,91 & 17,46 & 17,35 \\
\hline $\mathrm{J}$ & 1,39 & 1,39 & 6,37 & 6,45 \\
\hline K & 0,53 & 0,52 & 3,30 & 3,36 \\
\hline $\mathrm{L}$ & 3,72 & 3,72 & 17,95 & 17,73 \\
\hline M & 5,34 & 5,36 & 18,67 & 18,72 \\
\hline $\mathrm{N}$ & 3,31 & 3,30 & 13,91 & 14,18 \\
\hline $\mathrm{O}$ & 4,31 & 4,29 & 20,62 & 20,74 \\
\hline $\mathrm{P}$ & 4,91 & 4,92 & 20,71 & 21,08 \\
\hline
\end{tabular}




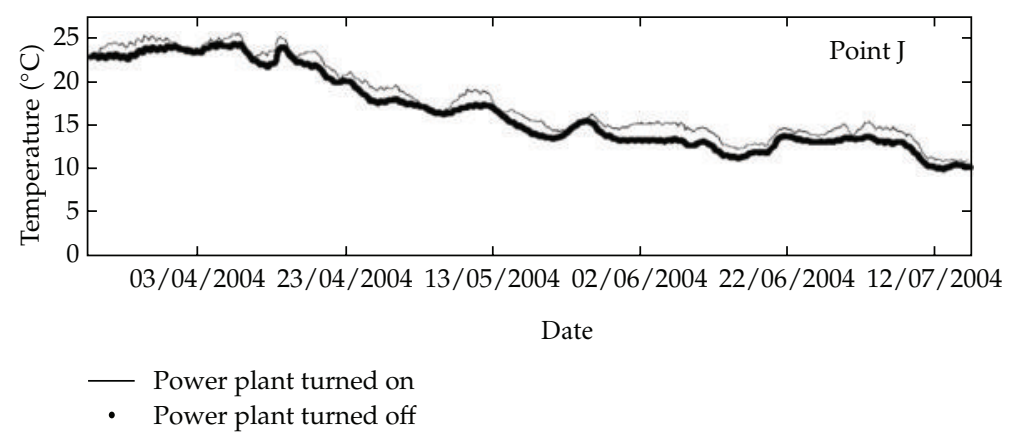

(a)

\begin{tabular}{lc}
\hline \multicolumn{1}{c}{$\Delta T$} & Frequency $(\%)$ \\
\hline$<0$ & 0 \\
$<0.2$ & 7.2 \\
$<0.4$ & 13.3 \\
$<0.6$ & 21.1 \\
$<0.8$ & 29.9 \\
$<1$ & 44.1 \\
$<1.2$ & 56.7 \\
$<1.4$ & 72.7 \\
$<1.6$ & 88.6 \\
$<1.8$ & 94.1 \\
$<2$ & 99.5 \\
$<2.2$ & 100 \\
\hline
\end{tabular}

(b)

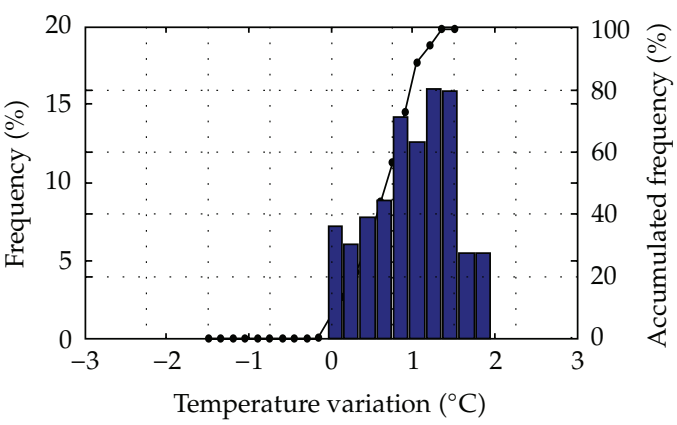

(c)

Figure 18: Time evolution of the water temperature calculated with the model in the zone inside the port (point J) with the power plant turned on and turned off. Histogram of the $\Delta T$ in point J.

\section{Conclusions}

A good representation of the temporal variations of temperature in the Montevideo Bay was obtained with the implementation, calibration, and validation of the finite element model RMA-10 in its vertically integrated two-dimensional mode.

The model can correctly represent the water temperature in the intake and in the discharge of the plant. Comparing the results of the model with the power plant turned on and off, it is possible to determine the effect of the power plant on the temperature field.

One of the objectives of this work was to determine the size and spatial distribution of the thermal plume resulting from the power plant discharge. The predictive computer model developed for this study shows the areas of the thermal plume (or mixing zone) in which the temperature decreases sufficiently to approach the far field values of temperature. Using this information, the study suggests a number of conclusions which are discussed below.

(i) Spatial distribution. Various simulations performed for the summer and winter of 2004 showed that the spatial distribution of the thermal plume is variable. On March 30th, the thermal plume extended in a northerly direction, reaching the plant water intake. On other occasions, such as June 17th (Figure 14), the plume extended in a narrower area of the port. However, at times, the plume also extended more than one kilometer beyond the discharge. The spatial distribution of the thermal plume is undoubtedly affected by wind patterns and other phenomenon such as tide effects (i.e., the naturally occurring back and forth movement of water resulting in constantly changing water levels and velocities). 


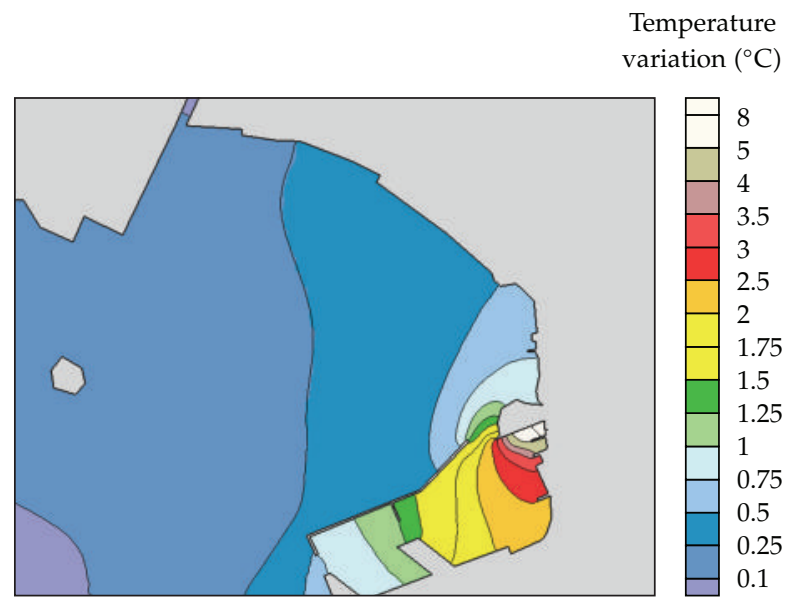

Figure 19: Spatial distribution of the mean increment water temperature generated by the outflow of power plant.

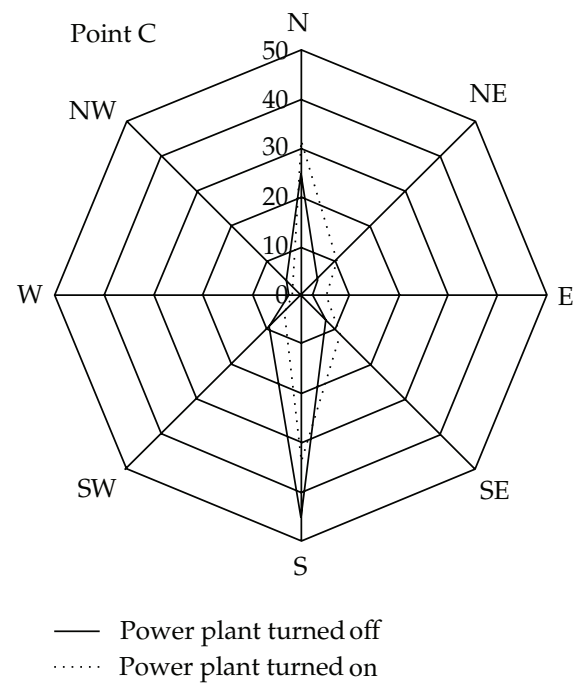

(a)

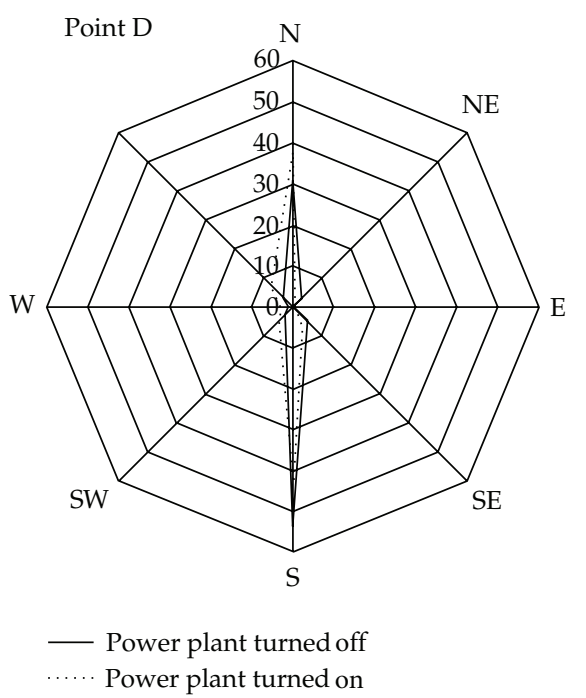

(b)

Figure 20: Directional frequency distribution in points $C$ and $D$ obtained in the simulation with the power plant and without the power plant.

(ii) Temperatures at the water intake. The study showed that during the period between March 19th and July 16th, 2004, 28.5\% of the time, the temperature of water reaching the water intake increases by at least $1^{\circ} \mathrm{C}$, while the maximum value of temperature increase during the simulation period was $2.3^{\circ} \mathrm{C}$.

The model simulations provide valuable information regarding the size, spatial distribution, and location of the thermal mixing zone. As discussed previously, the size and spatial distribution of the mixing zone tend to vary considerably from one day to another. However, in general, the size of the thermal plume extends to the west, north, and south of the discharge 


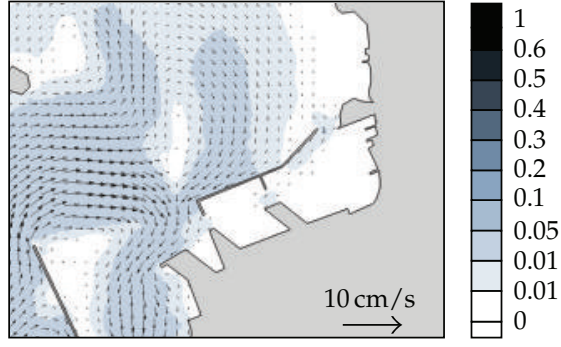

(a)

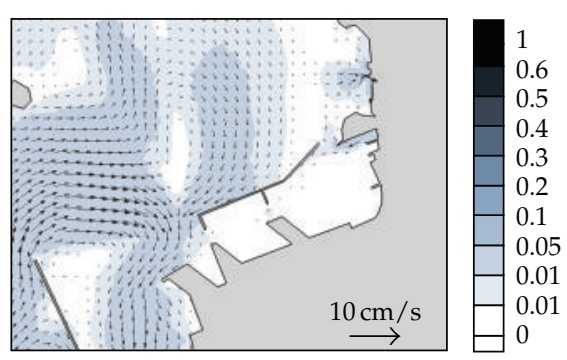

(b)

Figure 21: Mean field currents in the simulation with power plant turned off (a) and power plant turned on (b). Velocities in $\mathrm{cm} / \mathrm{s}$.

point. Figure 19 shows the time average temperature field (from March 19th to July 16th, 2004) obtained averaging instantaneous differences between the thermal field obtained with the power plant on and off. Near the water intake, the mean value of temperature increase was $0.75^{\circ} \mathrm{C}$.

Discharge-induced mixing is generally defined as the area where active mixing of the discharge plume and dilution of water is occurring. Beyond that area, the mixing becomes more passive or random, while the plume becomes much more disperse. Given these characterizations, model results suggest that discharge-induced mixing generally ceases just beyond the west end of the jetty located between the port and the bay, and so, this mixing zone is limited to a narrow zone near the discharge point.

In addition, it was observed that the modification of the circulation pattern induced by the intake discharge of cooling water is limited to the thermal plume area. However, it is found that residual currents produced when the power plant is operating show a very distinctive pattern. In that circumstance, the circulation pattern shows a predominant flow from the discharge zone to the bay and towards the power plant water intake. When the power plant is off, the circulation pattern reverses, that is, from the bay towards the port.

\section{References}

[1] M. Abbaspour, A. H. Javid, P. Moghimi, and K. Kayhan, "Modeling of thermal pollution in coastal area and its economical and environmental assessment," International Journal of Environmental Science and Technology, vol. 2, no. 1, pp. 13-26, 2005.

[2] S. A. Lowe, F. Schuepfer, and D. J. Dunning, "Case study: three-dimensional hydrodynamic model of a power plant thermal discharge," Journal of Hydraulic Engineering, vol. 135, no. 4, pp. 247-256, 2009.

[3] D. G. Kim and H. Y. Cho, "Modeling the buoyant flow of heated water discharged from surface and submerged side outfalls in shallow and deep water with a cross flow," Environmental Fluid Mechanics, vol. 6, no. 6, pp. 501-518, 2006.

[4] G. H. Jirka, "Multiport diffusers for heated disposal: a summary," Journal of the Hydraulics Division, vol. 108, no. 12, pp. 1425-1468, 1982.

[5] S. H. Chieh, "Two-dimensional numerical model of thermal discharges in coastal regions," Journal of Hydraulic Engineering, vol. 113, no. 8, pp. 1032-1040, 1987.

[6] J. M. Beckers and J. J. Van Ormelingen, "Thermohydrodynamical modelling of a power plant in the Zeebrugge Harbour," Journal of Hydraulic Research, vol. 33, no. 2, pp. 163-180, 1995.

[7] Y. Yunli, W. Deguan, W. Zhigang, and L. Xijun, "Numerical simulation of thermal discharge based on FVM method," Journal of Ocean University of China, vol. 5, no. 1, 2006.

[8] I. P. King, RMA-10 A finite element model for three-dimensional density stratified flow, Department of Civil and Environmental Engineering, University of California, Davis, Calif, USA, 1993. 
[9] Golder Associates Ltd., "The modelling assessment of thermal effects of Genesee plant cooling water discharge," Report to EPCOR, Edmonton, Alberta, Canada, May 2001.

[10] I. Piedra-Cueva and M. Fossati, "Residual currents and corridor of flow in the Rio de la Plata," Applied Mathematical Modelling, vol. 31, no. 3, pp. 564-577, 2007.

[11] M. Fossati and I. Piedra-Cueva, "Numerical modelling of residual flow and salinity in the Río de la Plata," Applied Mathematical Modelling, vol. 32, no. 6, pp. 1066-1086, 2008. 


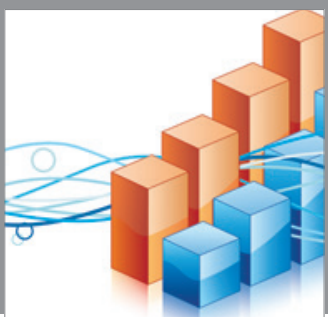

Advances in

Operations Research

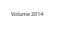

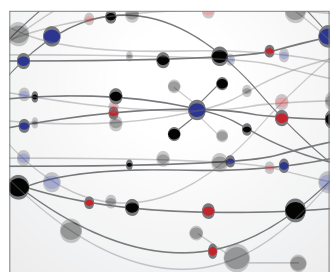

\section{The Scientific} World Journal
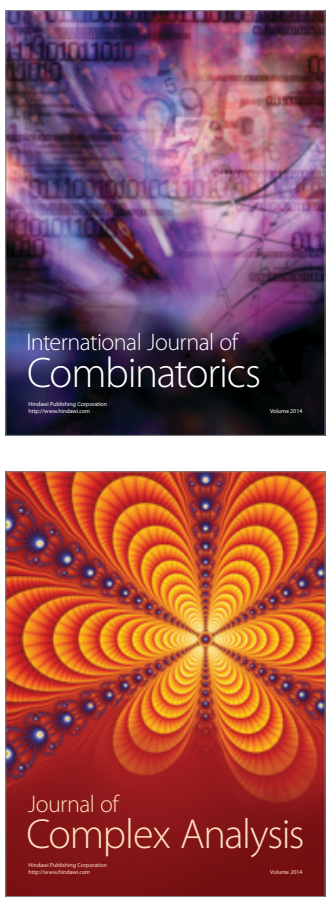

International Journal of

Mathematics and

Mathematical

Sciences
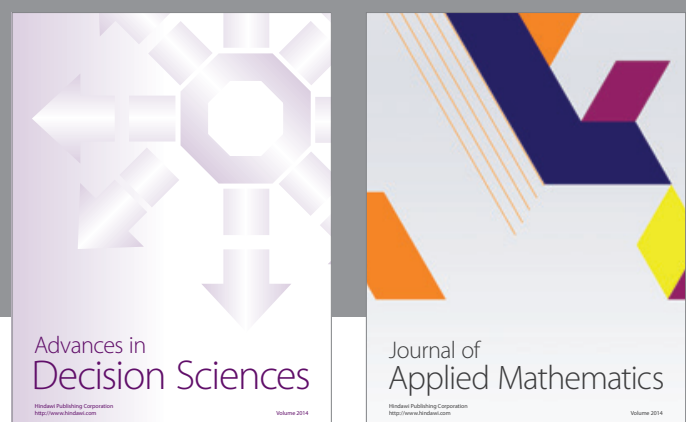

Journal of

Applied Mathematics
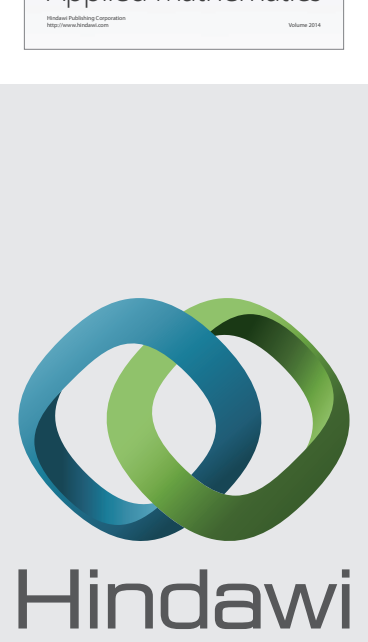

Submit your manuscripts at http://www.hindawi.com
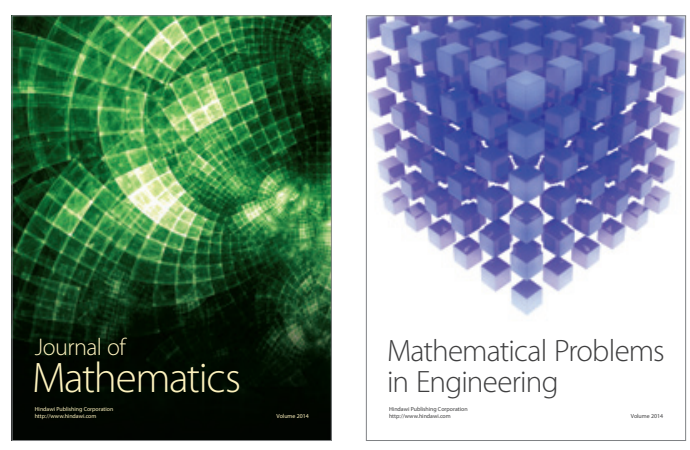

Mathematical Problems in Engineering
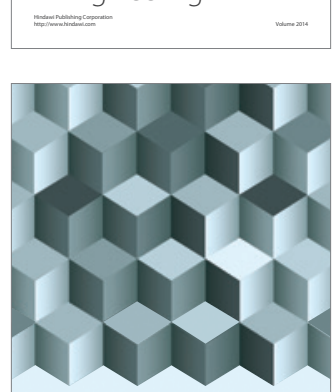

Journal of

Function Spaces
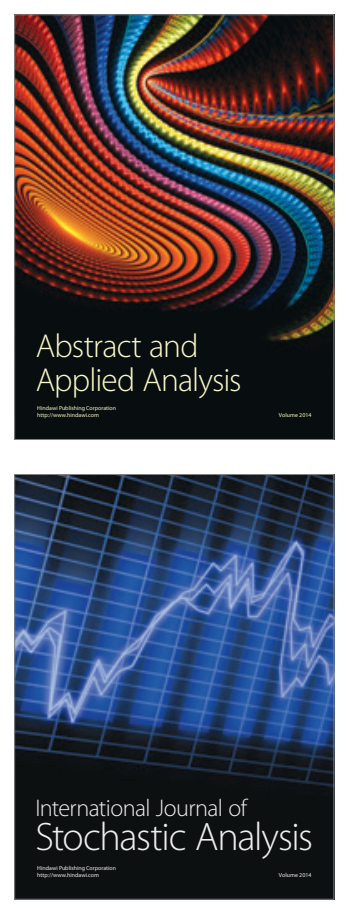

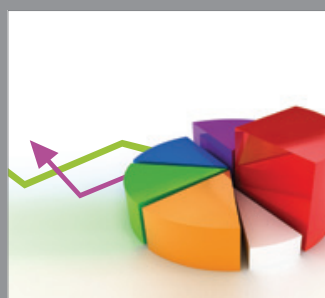

ournal of

Probability and Statistics

Promensencen
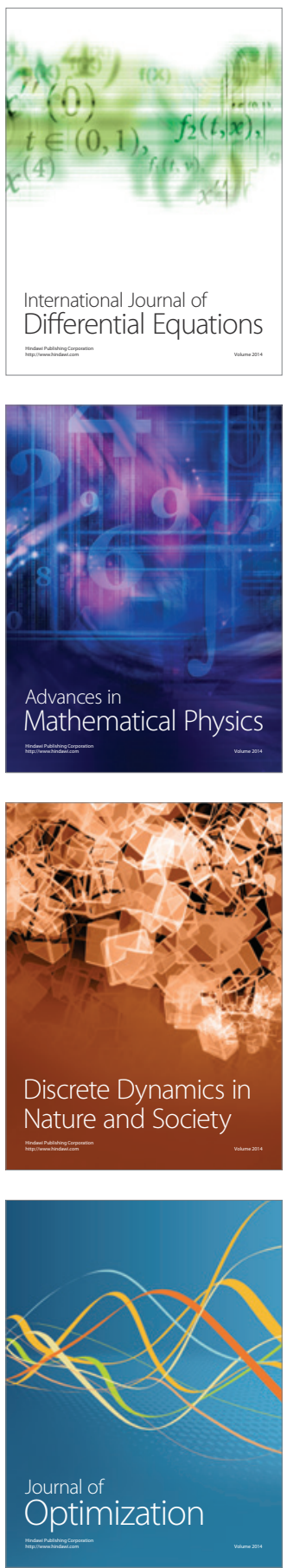